\title{
Macrocyclic vs. Linear Polymer Formation in the Coordination- Insertion Polymerization of Cyclic Carbonates
}

\author{
Gabriel Rokicki, ${ }^{\dagger}$ Anna Piotrowska, and Piotr PAwŁowsKi
}

Warsaw University of Technology, Faculty of Chemistry, ul. Noakowskiego 3, Warsaw 00-664, Poland

(Received June 5, 2002; Accepted November 23, 2002)

\begin{abstract}
Investigations on the mechanistic aspects of the coordination-insertion polymerization of sixmembered cyclic carbonate 5,5-dimethyl-1,3-dioxan-2-one (DTC) initiated by tin(II) alkoxide-based catalysts are presented. ${ }^{1} \mathrm{H}$ NMR and MALDI-TOF mass spectrometric analyses of the DTC polymerization products revealed that predominantly macrocyclic oligocarbonates are formed in the presence of a stannane catalyst. It was found that the addition of a small amount of water or diol suppresses the macrocyclization and linear polycarbonates can be obtained. The plausible mechanism of macrocyclization and linear product formation is proposed and discussed.

KEY WORDS Dialkoxytin(II) Catalysts / Coordination Polymerization / Cyclic Carbonate / Macrocyclization / Polycarbonates / MALDI-TOF Mass Spectrometry /
\end{abstract}

Biodegradable and biocompatible polymers such as aliphatic polyesters and polycarbonates are usually synthesized employing ring-opening polymerization of small size cyclic monomers (lactides, lactones or sixmembered cyclic carbonates). Metal alkoxides or metal carboxylates are usually used as catalysts for controlled polymerization leading to a polymer of predictable molecular weight, narrow molecular weight distribution and containing appropriate end groups. Tin- and aluminum-based catalysts are most frequently used in the coordination polymerization of heterocyclic monomers. Extensive work has been carried out to explain the mechanism and kinetics of cyclic monomers polymerization in the presence of these catalysts.

Unfortunately, there are a number of inconsistent data from the investigation on the cyclic esters polymerization mechanism in the presence of metal alkoxide catalysts. Stridsberg et al. reported no macrocycle formation during the polymerization of L-lactide in the presence of dialkylstanna-2,5-dioxacyclopentane, but the hydroxy-telechelic polyester was exclusively obtained. ${ }^{1}$ Recently, Montaudo et al. have found that Llactide polymerized in the presence of aluminum alkoxide derived from Schiff's base led to linear as well as macrocylic polymers. The presence of macrocycles was confirmed by MALDI-TOF mass spectrometric analysis. ${ }^{2}$

The formation of odd-membered polylactide macromolecules as results from the L-lactide (a dimer of lactic acid) polymerization was explained on the basis of ester-exchange reactions, which proceeds in parallel to the polymerization process, causing a random cleavage of the polylactide chain. The intramolecular reaction

${ }^{\dagger}$ To whom correspondence should be addressed. occurs by a partial depolymerization reaction leading to the formation of cyclic oligomers. The ring-chain equilibration reactions may be thermodynamically or kinetically controlled and cyclic oligomers of relatively low molecular weight but in a low concentration are produced. $^{3}$

Similarly, Sosnowski et al. reported that in the ring-opening polymerization initiated by 2,2-dibutyl-2stanna-1,3-dioxepane the concentration of the resulting polylactide macrocycles was higher than that of linear macromolecules in the fraction up to $c a .1500 \mathrm{Da}^{4}{ }^{4}$ The share of macrocycles decreased with the growth of the polymer molecular weight. The authors concluded that the reaction proceeds with the insertion of the monomer at both $\mathrm{Sn}-\mathrm{O}$ bonds of the catalyst. ${ }^{1,4}$

Knani et al. studied the ring-opening polymerization of $\varepsilon$-caprolactone ( $\varepsilon$-CL) catalyzed by porcine pancreatic lipase (PPL) initiated by methanol and observed, besides dilactone and poly( $\varepsilon$-caprolactone), the presence of larger cyclic oligomers. 5,6

Recently, Kowalski et al. found that true initiating species of $\varepsilon$-caprolactone polymerization are formed in situ by converting $\mathrm{Sn}(\mathrm{Oct})_{2}$ into OctSnOR and $\mathrm{Sn}(\mathrm{OR})_{2}$ in the reaction with hydroxyl containing compounds present in a residual amount in the reaction system. ${ }^{7}$ Moreover, the polymerization of $\varepsilon$-caprolactone carried out in the presence of dialkoxytin(II) proceeds much faster than that in the presence of $\mathrm{Sn}(\mathrm{Oct})_{2}{ }^{8}$ In this case also both cyclic and linear oligomers were formed.

Kricheldorf et al. ${ }^{9}$ observed the formation of macrocyclic polycarbonate in the case of using 2,2-dibutyl-2stanna-1,3-dioxepane as a catalyst in the polymerization of trimethylene carbonate and 2,2-dimethyl-1,3dioxan-2-one. For the latter monomer rapid degradation and chain transfer reactions prevented the obtain- 
ing high molecular weight polymers. The authors suggested that in contrast to the polymerization of lactones, the elimination of 2-stanna-1,3-cycloalkane can occur and tin-free macrocyclic products are formed.

In the present paper we report the investigations on the mechanistic aspects of the coordination polymerization of six-membered cyclic carbonates initiated by tin(II) alkoxide-based catalysts. The results of MALDITOF mass spectrometry analysis will be utilized to understand the influence of the stannane catalyst, reaction conditions and presence of water or alcohol on linear vs. macrocyclic products formation. Polycarbonates terminated with $\mathrm{OH}$ groups can be employed as soft segments in polyurethane production, so the end groups play a crucial role. The presence of macrocyclic products as well as linear ones terminated with alkoxy, acyl, or alkyl carbonate groups can disturb the polyurethane synthesis.

\section{EXPERIMENTAL}

\section{Materials}

$\mathrm{SnCl}_{2}$ (Aldrich) was used after drying with $\mathrm{CaCl}_{2}$ and acetic anhydride. Trietylamine (Aldrich) was dried with $\mathrm{KOH}$ and distilled under vacuum. 2-Methylpropane-1,3-diol, 2,2-dimethylpropane1,3-diol, o-phenylenediamine and salicylaldehyde (Aldrich) were used as received. SnOct 2 (Laboratory of Technological Processes, Warsaw). Dimethoxytin(II) was obtained in the reaction of $\mathrm{SnCl}_{2}$ with methyl alcohol in the presence of triethylamine according to ref 10. Cyclic carbonate (5,5-dimethyl-1,3-dioxan-2-one, DTC) was prepared from diethyl carbonate and 2,2dimethylpropane-1,3-diol using $\mathrm{Sn}(\mathrm{Oct})_{2}$ as a catalyst according to the known method. ${ }^{11}$ Solvents were dried by conventional methods and distilled under nitrogen.

\section{Measurements}

${ }^{1} \mathrm{H}$ NMR and ${ }^{13} \mathrm{C}$ NMR spectra were recorded on a Varian VXR $400 \mathrm{MHz}$ spectrometer. Deuterated solvents were used and tetramethylsilane served as internal standard. IR spectra were recorded on Biorad FTIR spectrometer as $\mathrm{KBr}$ pellets. MALDI-TOF spectra were recorded on a Kratos Kompact MALDI 4 V5.2.1 apparatus equipped with a $337 \mathrm{~nm}$ nitrogen laser with a $3 \mathrm{~ns}$ pulse duration. The measurements were carried out in the linear mode of the instrument at an acceleration voltage of $+20 \mathrm{kV}$. For each sample, spectra were averaged over 200 laser shots. The samples were dissolved in THF $\left(5 \mathrm{mg} \mathrm{cm}^{-3}\right)$ and mixed with a solution of the MALDI-TOF matrix (2,5-dihydroxybenzoic acid, $0.2 \mathrm{M}$ in THF) and $\mathrm{NaI}$ as an ionization promoter. The laser power was moderated in the range of 120-130 units characteristic for this apparatus in order to avoid distortion of the mass spectrum.

\section{Kinetic Experiments}

Solution kinetics was obtained using a Specord 71 IR spectrophotometer cell accessory. The background spectrum was taken with toluene in the cell. Standard solutions of 5,5-dimethyl-1,3-dioxan-2-one and poly (DTC) in toluene were used to calibrate the instrument. Linearity of the absorbance of the cyclic carbonate $770 \mathrm{~cm}^{-1}$ and linear carbonate $750 \mathrm{~cm}^{-1}$ vs. their concentrations was confirmed.

\section{Syntheses of Tin(II)-Based Catalysts}

5-Methyl-2-stanna-1,3-dioxane was prepared according to ref 12 by heating dimethoxytin(II) ( $2 \mathrm{~g}$, $0.011 \mathrm{~mol})$ with 2-methylpropane-1,3-diol (1 g, 0.011 $\mathrm{mol})$ in toluene $\left(50 \mathrm{~cm}^{3}\right)$ for $2 \mathrm{~h}$ and removing methanol by distillation. Toluene and methanol residue were evaporated under vacuum from the post-reaction mixture. A $1.7 \mathrm{~g}$ of a white crystal powder was obtained after recrystallization from toluene (yield $74 \%$ ).

$\mathrm{C}_{4} \mathrm{H}_{8} \mathrm{O}_{2} \mathrm{Sn}$ (206.71): Calcd. Sn 57.38, C 23.24, H 3.90; Found: Sn 57.22, C 22.13, H 4.16

FT-IR (KBr): 2955 (m), 2846 (m), 1450 (s), 1280 (m), $850(\mathrm{~m}), 570(\mathrm{~s}) \mathrm{cm}^{-1}$.

${ }^{1} \mathrm{H}$ NMR $400 \mathrm{MHz}\left(\mathrm{CDCl}_{3}\right): \delta(\mathrm{ppm})=3.80,3.64$ and $3.51\left(\mathrm{~m}, \mathrm{t}, \mathrm{m}, 4 \mathrm{H}, \mathrm{SnOCH}_{2}-\right), 2.25-2.02(\mathrm{~m}, 1 \mathrm{H},-$ $\left.\mathrm{CH}_{2} \mathrm{C} \underline{\mathrm{H}}\left(\mathrm{CH}_{3}\right) \mathrm{CH}_{2}-\right), 0.92$ (d, 3H, $\left.-\mathrm{CHCH}_{3}\right)$.

Dibenzyloxy- and dilauryloxytin(II) catalysts were obtained in the reaction of dimethoxytin(II) with benzyl and lauryl alcohols, respectively in a similar manner as 5-methyl-2-stanna-1,3-dioxane was obtained. The catalyst containing both alkoxy and carboxylic groups was prepared in the reaction of $\mathrm{Sn}(\mathrm{Oct})_{2}$ with an equimolar amount of lauryl alcohol by exchanging octoate groups in $\mathrm{Sn}(\mathrm{Oct})_{2}$ and removing octanoic acid.

\section{Synthesis of $\left\{2,2^{\prime}-[1,2-\right.$ phenylenebis(nitrilomethyli- dene)]diphenolate\}tin [(SALEN)Sn]}

$\left\{2,2^{\prime}\right.$-[1,2-Phenylenebis(nitrilomethylidene)]diphenolate\}tin was prepared by heating under reflux $o$ phenylenediamine $(1 \mathrm{~g}, 0.009 \mathrm{~mol})$ and salicylaldehyde $(2.2 \mathrm{~g}, 0.018 \mathrm{~mol})$ in a mixture of dichloromethane $\left(40 \mathrm{~cm}^{3}\right)$ and methanol $\left(80 \mathrm{~cm}^{3}\right)$. After $1 \mathrm{~h}$ tin octoate $(2.5 \mathrm{~g}, 0.009 \mathrm{~mol})$ was added and the flask content was stirred for additional $3 \mathrm{~h}$. The resulting reddish powder was filtered off and dried under vacuum. $2.2 \mathrm{~g}$ of (SALEN)Sn was obtained ( $56 \%$ yield).

FT-IR (KBr): $2930(v \mathrm{CH}), 1030(v \mathrm{C}-\mathrm{O}), 560(\delta \mathrm{Sn}-$ O) $\mathrm{cm}^{-1}$.

${ }^{1} \mathrm{H}$ NMR $400 \mathrm{MHz}(\mathrm{DMSO}): \delta(\mathrm{ppm})=8.67(\mathrm{~s}, 2 \mathrm{H}$, $\mathrm{ArC} \underline{\mathrm{H}}=\mathrm{N}-), 7.78(\mathrm{~m}, 2 \mathrm{H}), 7.49(\mathrm{~m}, 2 \mathrm{H}), 7.43-7.32(\mathrm{~m}$, 
4H) $6.73-6.64(\mathrm{~m}, 4 \mathrm{H})$.

$\mathrm{C}_{20} \mathrm{H}_{14} \mathrm{~N}_{2} \mathrm{O}_{2} \mathrm{Sn}$ (432.94): Calcd. Sn 27.39, C 55.49, H 3.26, N 6.47; Found: Sn 27.28, C 55.33, H 3.46, N 6.40 .

\section{Polymerization of DTC}

The polymerizations of cyclic carbonate (DTC) were carried out in dry $25 \mathrm{~cm}^{3}$ serum bottles. The monomer was added to these vials in an amount of $1 \mathrm{~g}(8 \mathrm{mmol})$ together with $0.08 \mathrm{mmol}$ of a catalyst. The bottles were sealed and flushed with nitrogen and thermostated at an appropriate temperature. Solution polymerizations were performed in toluene, 1,4-dioxane and propylene carbonate, and terminated by precipitation in cold methanol.

\section{RESULTS AND DISCUSSION}

The dialkoxytin(II) catalysts [5-methyl-2-stanna-1,3dioxane (MSD), dibenzyloxy- and dilauryloxytin(II)] for the polymerization of six-membered cyclic carbonate were obtained from $\mathrm{SnCl}_{2}$ through dimethoxytin(II) by exchanging methoxy groups with higher alcohols according to the method reported by Kowalski et al. ${ }^{12}$ The catalyst containing both alkoxy and carboxylic groups was prepared by the partial ( $c a$. $50 \mathrm{~mol} \%$ ) exchange of an octanoic acid residue with lauryl alcohol in commercially available $\mathrm{Sn}(\mathrm{Oct})_{2}$.

It was found that the rate of the polymerization of 5,5-dimethyl-1,3-dioxan-2-one (DTC) carried out in the presence of 5-methyl-2-stanna-1,3-dioxane $\left(0.016 \mathrm{~mol} \mathrm{dm}^{-3}\right)$ in toluene was almost 9 times greater than that carried out in the presence of $\mathrm{Sn}(\mathrm{Oct})_{2}$ (lines 1 and 3, respectively, in Figure 1). In the case of using a tin-based catalyst containing both alkoxy and carboxylic groups the rate of polymerization was also distinctly greater than that catalyzed by tin octoate (line 2 , Figure 1). These results confirmed that in the polymerization of cyclic carbonates the true catalyst is produced in situ in the reaction of $\mathrm{Sn}(\mathrm{Oct})_{2}$ with diol or water residues, as was earlier postulated by Kowalski, Duda and Penczek ${ }^{7,8}$ for the polymerization of cyclic esters and discussed by Kricheldorf et al. ${ }^{9,13}$ for the polymerization of cyclic carbonates (Scheme 1).

However, the polymerization of six-membered cyclic carbonate carried out in the presence of tin(II) dialkoxide leads almost exclusively to macrocyclic oligocarbonates (Table I). The cyclic structure of the polycarbonate has been deduced from the lack of signals characteristic for methylene protons adjacent to the terminal hydroxyl groups in the respective ${ }^{1} \mathrm{H}$ NMR spectrum (Figure 2). In the ${ }^{1} \mathrm{H}$ NMR spectrum of the DTC polymerization products only two singlets $\left[3.97\left(\mathrm{CH}_{2}\right)\right.$

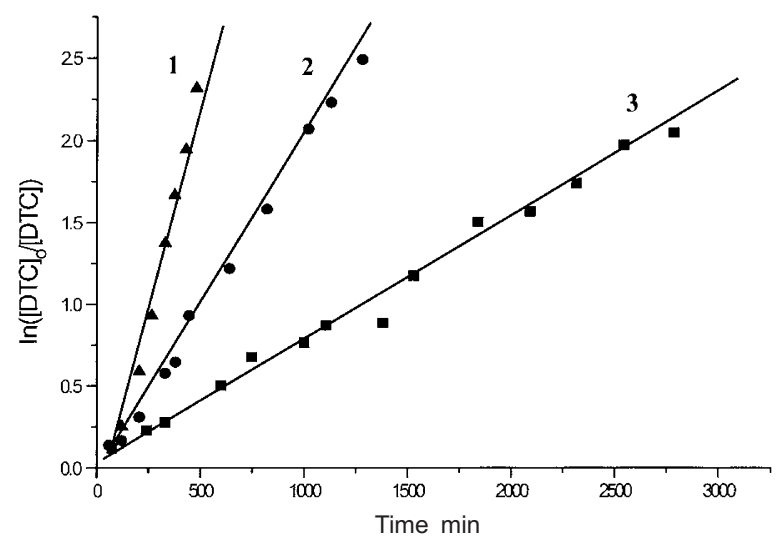

Figure 1. Kinetics of polymerization of cyclic carbonate (DTC) with tin(II)-based catalyst monitored IR-spectroscopically. Conditions: $[\mathrm{DTC}]_{0}=1.62 \mathrm{~mol} \mathrm{dm}^{-3}, \quad[\text { catalyst }]_{0}=0.0162$ mol dm ${ }^{-3}$, toluene solvent, $10{ }^{\circ} \mathrm{C} .1 ; \mathrm{Sn}\left(\mathrm{OCH}_{2} \mathrm{CH}\left(\mathrm{CH}_{3}\right) \mathrm{CH}_{2} \mathrm{O}\right)$, 2; $\mathrm{C}_{7} \mathrm{H}_{15} \mathrm{COOSnOC}_{12} \mathrm{H}_{25}, 3 ; \mathrm{Sn}\left(\mathrm{OOCC}_{7} \mathrm{H}_{15}\right)_{2}$.

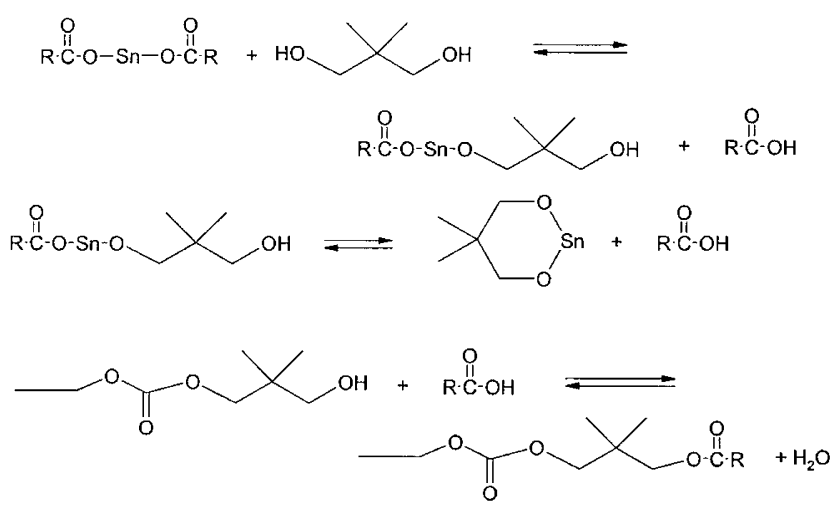

Scheme 1.

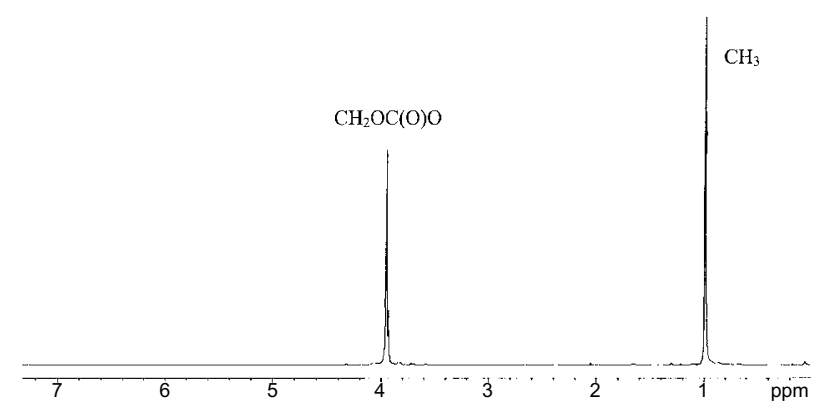

Figure 2. ${ }^{1} \mathrm{H} \mathrm{NMR}$ spectrum $\left(400 \mathrm{MHz}, \mathrm{CDCl}_{3}\right)$ of the product of the DTC polymerization carried out at $120^{\circ} \mathrm{C}$ in bulk, in the presence of $\mathrm{Sn}\left(\mathrm{OCH}_{2} \mathrm{CH}\left(\mathrm{CH}_{3}\right) \mathrm{CH}_{2} \mathrm{O}\right)(1 \mathrm{~mol} \%)$.

and $\left.0.96 \mathrm{ppm}\left(\mathrm{CH}_{3}\right)\right]$ are present. Taking into account that the same pattern of signals can be assigned to high molecular weight linear polycarbonate this result was verified by other analytical methods.

The presence of cyclic as well as linear oligomers with different end groups in the reaction products can be straightforwardly monitored by MALDI-TOF mass spectrometric analysis.

In Figure 3 the MALDI-TOF mass spectrum of the product of the polymerization of DTC carried out in the 
Table I. Ring-Opening Polymerization of DTC with Tin(II)-Based Catalysts

\begin{tabular}{|c|c|c|c|c|c|c|c|c|c|c|}
\hline $\begin{array}{c}\text { Run } \\
\text { no. }\end{array}$ & Catalyst & Solvent & $\begin{array}{l}\text { Temp. } \\
\left({ }^{\circ} \mathrm{C}\right)\end{array}$ & $\begin{array}{l}\text { Time } \\
(\min )\end{array}$ & $\begin{array}{c}\text { Conversion } \\
(\%)\end{array}$ & $M_{\mathrm{n}}^{\mathrm{a}}$ & $M_{\mathrm{n}}^{\mathrm{b}}$ & $M_{\mathrm{w}} / M_{\mathrm{n}}^{\mathrm{b}}$ & $\begin{array}{c}\text { Yield of } \\
\text { polycarbonate } \\
(\%)^{\mathrm{c}}\end{array}$ & $\begin{array}{c}\text { Yield of } \\
\text { macrocyclic } \\
\text { product }(\%)\end{array}$ \\
\hline $1^{\mathrm{d}}$ & $\begin{array}{l}\text { 5-methyl-2-stanna- } \\
\text { 1,3-dioxane }\end{array}$ & - & 120 & 30 & 95 & 1600 & 1470 & 1.4 & 87 & 96 \\
\hline $2^{\mathrm{e}}$ & & toluene & 100 & 520 & 86 & 1560 & 1400 & 1.4 & 93 & 98 \\
\hline $3^{\mathrm{e}}$ & & $\begin{array}{l}\text { propylene } \\
\text { carbonate }\end{array}$ & 120 & 520 & 68 & - & $1840^{1}$ & $1.5^{1}$ & 90 & 2 \\
\hline $4^{e}$ & & 1,4-dioxane & 100 & 1440 & 5 & - & - & - & - & no polymer \\
\hline $5^{\mathrm{df}}$ & & - & 120 & 22 & 87 & 1700 & 1250 & 1.4 & - & 87 \\
\hline $6^{\mathrm{dg}}$ & & - & 120 & 20 & 90 & 1900 & 1350 & 1.4 & - & 89 \\
\hline $7^{\mathrm{d}}$ & dimethoxytin(II) & - & 120 & 30 & 93 & - & 1100 & 1.3 & 88 & 90 \\
\hline $8^{\mathrm{d}}$ & dibenzyloxytin(II) & - & 120 & 40 & 95 & - & 1150 & 1.4 & - & 60 \\
\hline $9^{d}$ & dilauryloxytin(II) & - & 120 & 35 & 45 & - & 550 & 1.3 & - & 56 \\
\hline $10^{\mathrm{d}}$ & (SALEN)Sn & - & 120 & 1440 & 5 & - & - & - & - & no polymer \\
\hline
\end{tabular}

${ }^{a} \mathrm{GPC} .{ }^{\mathrm{b}} \mathrm{Calculated} \mathrm{from} \mathrm{MALDI-TOF} \mathrm{mass} \mathrm{spectrometry.}{ }^{\mathrm{c}}$ Yield of cyclic and linear polycarbonates was calculated from ${ }^{1} \mathrm{H}$ NMR spectra. ${ }^{\mathrm{d}}$ Polymerization was conducted in the presence of $1 \mathrm{~mol} \%$ of initiator. ${ }^{\mathrm{e}}$ Polymerization was conducted with $[\mathrm{M}]_{0}=1.62 \mathrm{M}$ and $[\mathrm{I}]=0.0162 \mathrm{M}$. ${ }^{\text {f }}$ Polymerization was carried out in the presence of a small amount of water $(0.1 \mathrm{~mol} \%)$. ${ }^{\text {g}}$ Polymerization was carried out in the presence of a small amount of 2,2-dimethyl-1,3-propanediol (0.01 mol).

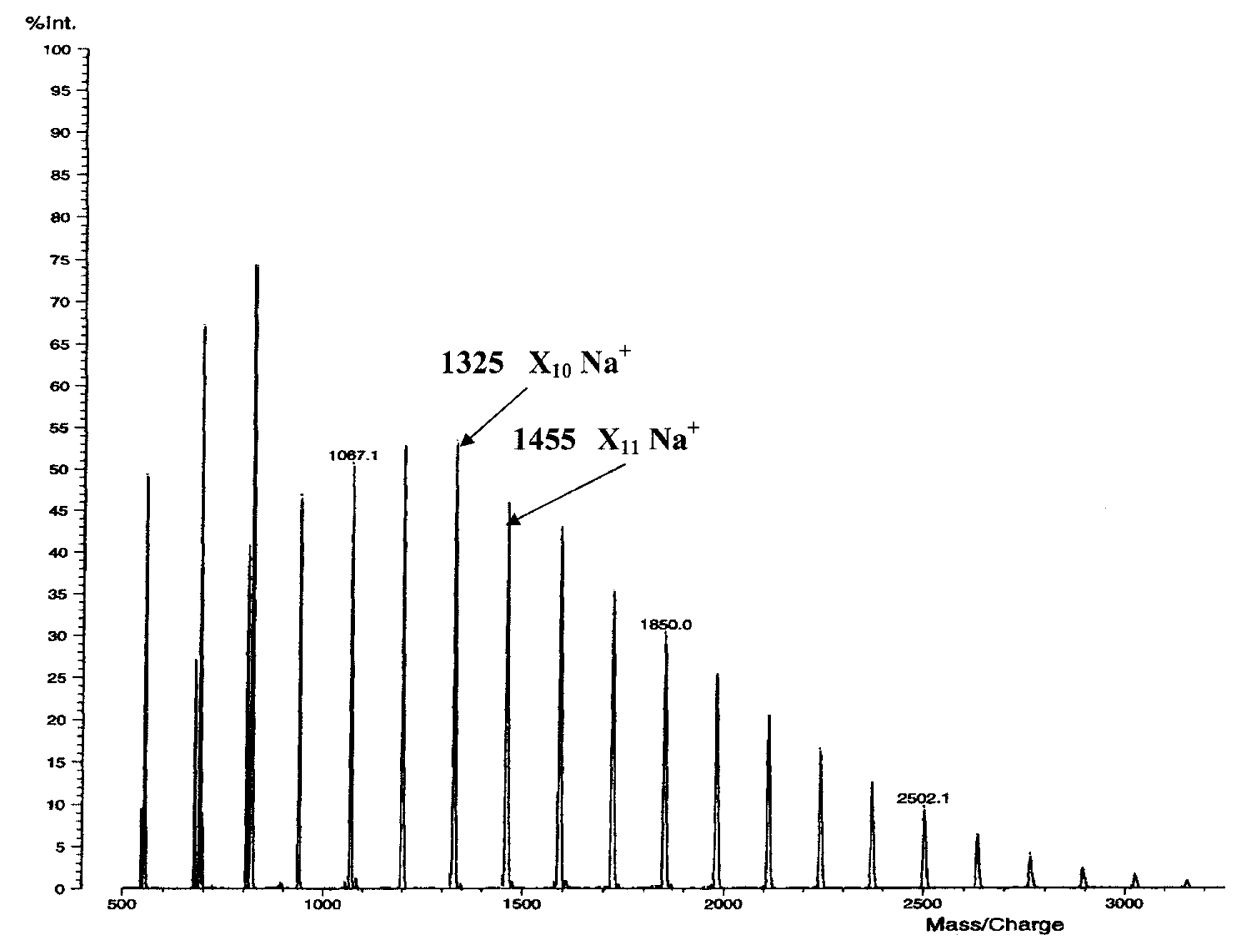

Figure 3. MALDI-TOF mass spectrum of poly(DTC) obtained by the polymerization of DTC carried out at $120^{\circ} \mathrm{C}$ in bulk, in the

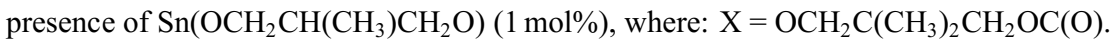

bulk at $120^{\circ} \mathrm{C}$ in the presence of 5-methyl-2-stanna1,3-dioxane $(1 \mathrm{~mol} \%)$ one series of signals is present, besides very small signals assigned to traces of linear products. The distance between each signal corresponds to $130 \mathrm{Da}$ (the molecular mass of the DTC unit). This series of signals (residual mass: $0 \mathrm{Da}$ ) can be assigned to cyclic oligomers of DTC of different molecular weight $\left(M_{\mathrm{n}}=1470, M_{\mathrm{w}} / M_{\mathrm{n}}=1.3\right)$. As can be noticed from Figure 3 and 5 the macromolecules did not contain the diol residue (2-methylpropan-1,3- diol) originated from the catalyst. This also indicates that no decarboxylation takes place during the polymerization of cyclic carbonate in the presence of the dialkoxytin(II) catalyst at relatively high temperature. In the case of the polymerization carried out in toluene $\left(100^{\circ} \mathrm{C}\right)$ also mainly macrocycles were produced but of lower molecular weights.

Generally, the formation of macrocyclic products is postulated to proceed through intramolecular transesterification. ${ }^{2-8}$ The concentration of cyclic oligomers 

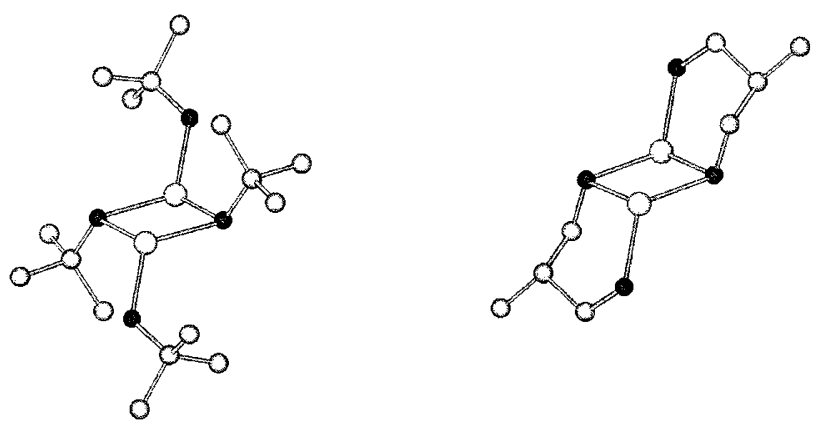

di-tert-butoxytin(II)

5-methyl-2-stanna-1,3-dioxane

Figure 4. 3D-structure of di-tert-butoxytin(II) from X-Ray analysis $^{18}$ and 5-methyl-2-stanna-1,3-dioxane modeled using molecular mechanics HyperChem 5.

according to Jacobson and Stockmayer, should be proportional to $n^{-2.5}$, where $n$ is the number of constitutional repeating units in the ring. ${ }^{14}$ Thus, the intensity of the signals should fall down with an increase in the polymer molecular weight. However, in the case of using the dialkoxytin(II) catalyst for the polymerization of cyclic carbonate the lack of linear products in the post-reaction mixture suggests that macrocycles are formed according to non-typical reaction mechanism.

Stannoxanes are known to exist as dimers bound via tricoordinated tin atoms. Veith et al. ${ }^{15}$ as well as McBurnett and Cowley ${ }^{16}$ have found that di-tertbutoxytin(II) forms a dimer with two kinds of oxygen atoms (Figure 4). Taking the above into account it is plausible that the cyclic dialkoxytin(II) catalyst can also form the tricyclic dimer. Unfortunately, our attempts of obtaining crystals of 5-methyl-2-stanna-1,3-dioxane (MSD) suitable for an X-Ray structure determination have failed. Thus, to explain the role of the dimer form of the catalyst in the polymerization of cyclic carbonates the molecular mechanics was used to model the geometry of the complex. Partial charges were assigned to the tin complex on the basis of semi-empirical (PM3) calculations and geometry of the complex was modeled using molecular mechanics. Optimizations were carried out using the HyperChem molecular modeling package (version 5.0) similarly to the method published by Kane et al. ${ }^{17}$ and the resulting structure is presented in Figure 4. It is characteristic that the X-Ray structure of the di-tert-butoxytin(II) complex obtained by Fieldberg et al. ${ }^{18}$ and Veith et al. ${ }^{15}$ was very similar to the structure simulated using the HyperChem program. On the other hand, the coordination compounds in solution represent a highly dynamic system, since even small differences in the polarity of the solution system may result in an effect on the coordination behavior and, thus, on the catalytic efficiency.


Scheme 2.

It is worth mentioning that also cyclic tin(IV) alkoxides exist in two forms being in equilibrium: as a monomer and as a dimeric compound. ${ }^{1,9,19-22}$

From the MALDI-TOF mass spectrometric analysis of the polymerization product one can notice that the cyclic macromolecules of polycarbonate did not contain a diol (2-methylpropan-1,3-diol) residue originated from the catalyst used. The lack of signals of the residual mass equal $116 \mathrm{Da}$ suggests that the insertion of the cyclic carbonate monomer proceeds into one kind of $\mathrm{Sn}-\mathrm{O}$ bond of the complex, that, in which the oxygen atom is not bridged with the second tin atom (Scheme 2).

Thus, one of the plausible mechanisms taken into consideration for the polymerization of six-membered cyclic carbonate was that in which the reaction proceeds via orthocarbonate species. The reaction pathway involves monomer coordination through the oxygen atom of the carbonyl group (I), cleavage of the $\mathrm{C}(\mathrm{O})-\mathrm{O}$ bond leading to orthocarbonate species (II), and then after the rearrangement, the formation of a new tin-alkoxide bond (III) (Scheme 2).

Consequently, taking into account the polymerization mechanism proposed above, the macrocycles formation can be explained to proceed according to the same reaction mechanism but in the opposite direction (Scheme 3).

Molecular weights of macrocyclic oligomers depend on the monomer/initiator ratio only for small values, but for larger values, the ring-closing termination of the polycarbonate polymerization proceeds according to statistical rules. The reverse and direct reactions are permitted with the same probability, so that an initial 


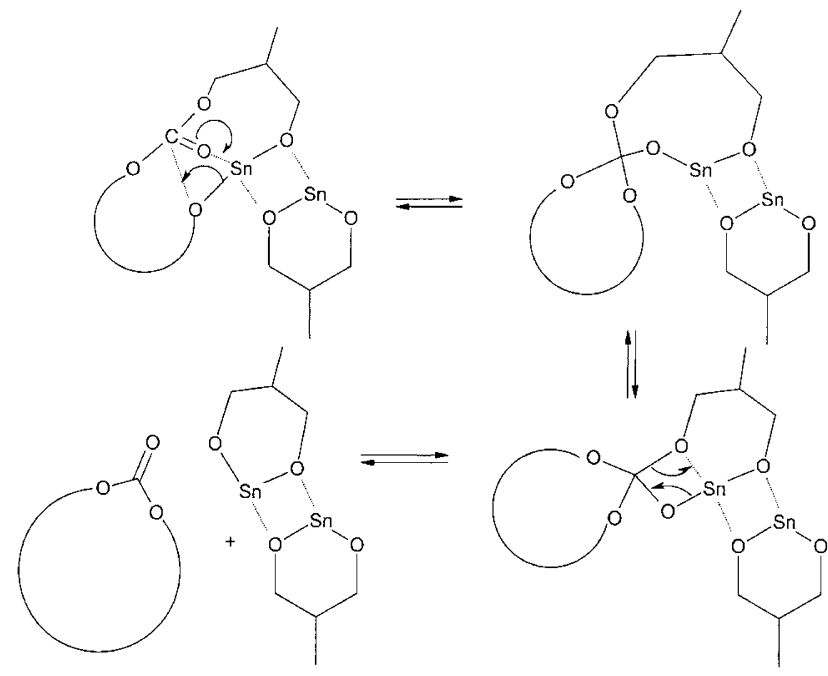

Scheme 3.
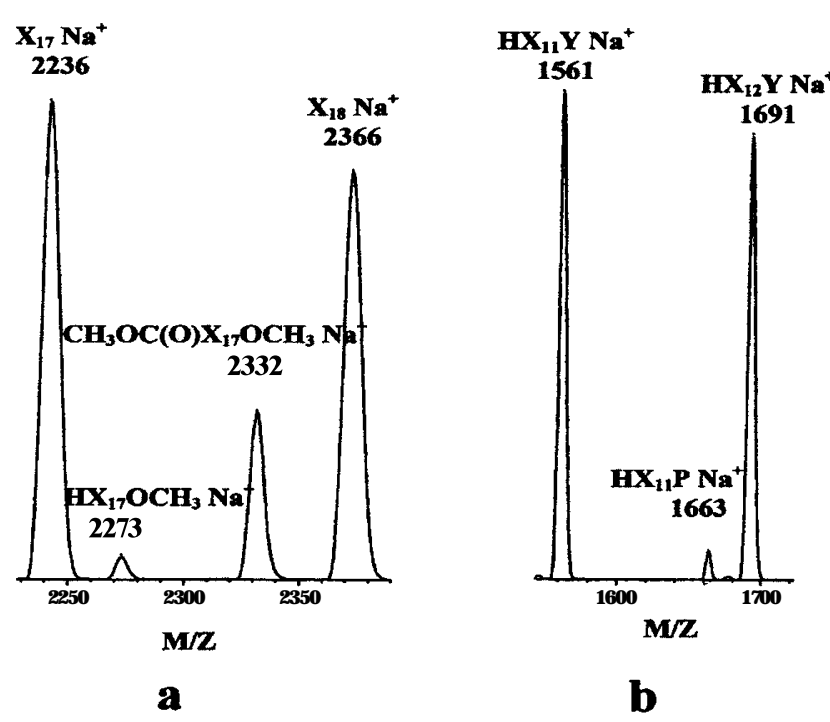

Figure 5. Fragments of the MALDI-TOF mass spectrum of poly(DTC) obtained by the polymerization of DTC carried out at $120^{\circ} \mathrm{C}$. a; in the bulk in the presence of $\left(\mathrm{CH}_{3} \mathrm{O}\right)_{2} \mathrm{Sn}$ $(1 \mathrm{~mol} \%), \mathrm{b}$; in a propylene carbonate solution $(40 \mathrm{wt} \%)$, in the presence of $\mathrm{Sn}\left(\mathrm{OCH}_{2} \mathrm{CH}\left(\mathrm{CH}_{3}\right) \mathrm{CH}_{2} \mathrm{O}\right)(1 \mathrm{~mol} \%)$; where: $\mathrm{X}=\mathrm{OCH}_{2} \mathrm{C}\left(\mathrm{CH}_{3}\right)_{2} \mathrm{CH}_{2} \mathrm{OC}(\mathrm{O}), \mathrm{Y}=\mathrm{OCH}_{2} \mathrm{C}_{2}\left(\mathrm{CH}_{3}\right)_{2} \mathrm{CH}_{2} \mathrm{OH}, \mathrm{P}=$ $\mathrm{OCH}_{2} \mathrm{CH}\left(\mathrm{CH}_{3}\right) \mathrm{OH}$ or $\mathrm{OCH}\left(\mathrm{CH}_{3}\right) \mathrm{CH}_{2} \mathrm{OH}$.

population of cyclic oligomers evolves towards equilibrium distributions of rings of different size.

No reaction progress was observed when 1,4-dioxane was used as the reaction medium. The active sites in the tricoordinated tin catalyst were probably blocked by the ether-based solvent.

When "linear" dimethoxy-, dibenzyloxy- or dilauryloxytin(II) catalysts were used, in the products besides macrocyclic oligomers polycarbonates terminated with methyl, benzyl or lauryl groups as well as $\mathrm{OH}$ group were present, respectively. In the MALDI-TOF spectra a respective series of signals corresponding to the above mentioned species can be seen (Figure 5a).

When acyclic dialkoxytin(II) catalysts were used for

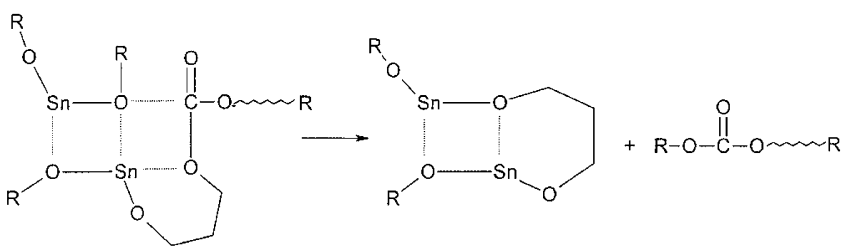

Scheme 4.
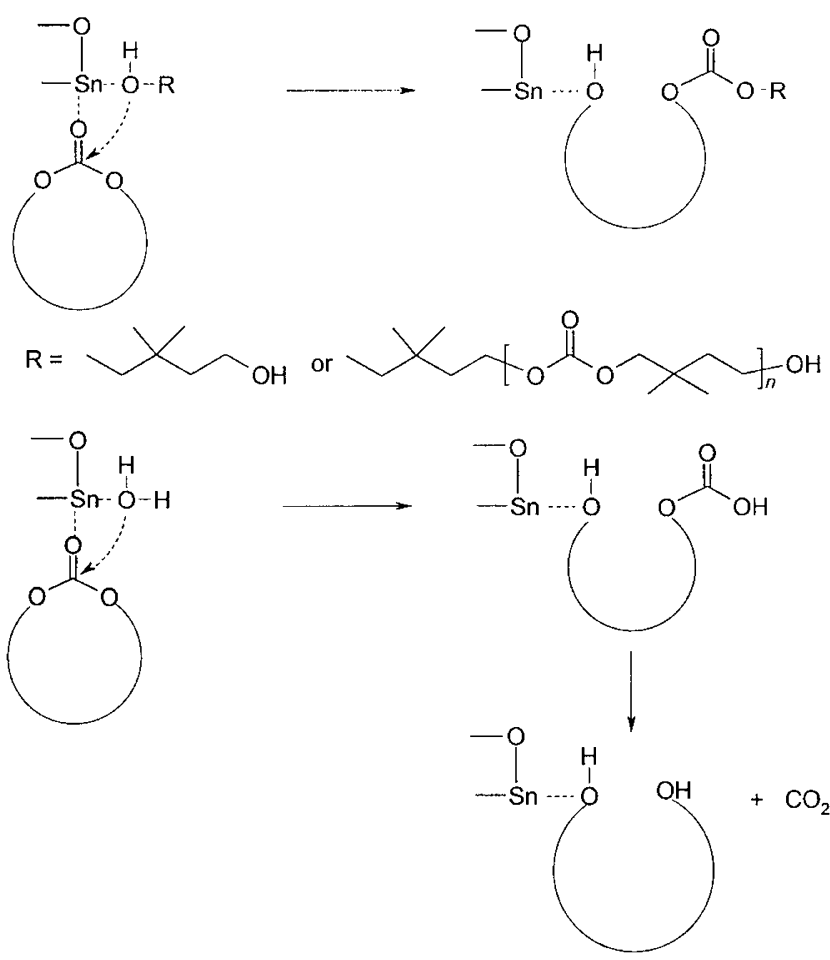

Scheme 5.

the polymerization of the carbonate monomer, cyclic stannoxanes (2-stanna-1,3-dioxane) can be formed in situ according to the reaction mechanism presented in Scheme 4.

No polymerization took place when the tin(II)-based catalyst with occupied four coordination sites, such as tin(II) phenoxide derived from a Schiff's base, namely $\left\{2,2^{\prime}-[1,2-\right.$ phenylenebis(nitrilomethylidene)]diphenolate $\}$ tin [(SALEN)Sn] was used.

It was found that the addition of a small amount of diol or water into the reaction system leads to the formation of linear macromolecules terminated with $\mathrm{OH}$ groups (Figure 6). The intermolecular reaction with diol, oligomer terminated with $\mathrm{OH}$ groups or water proceeds through the activated polycarbonate macrocycle by tin(II) alkoxide according to the mechanism presented in Scheme 5.

When the polymerization of DTC catalyzed by MSD was carried out in propylene carbonate as a reaction medium, practically no insertion of five-membered cyclic carbonate into the polymer chain was observed. Surprisingly, only linear poly(DTC) was obtained. In 


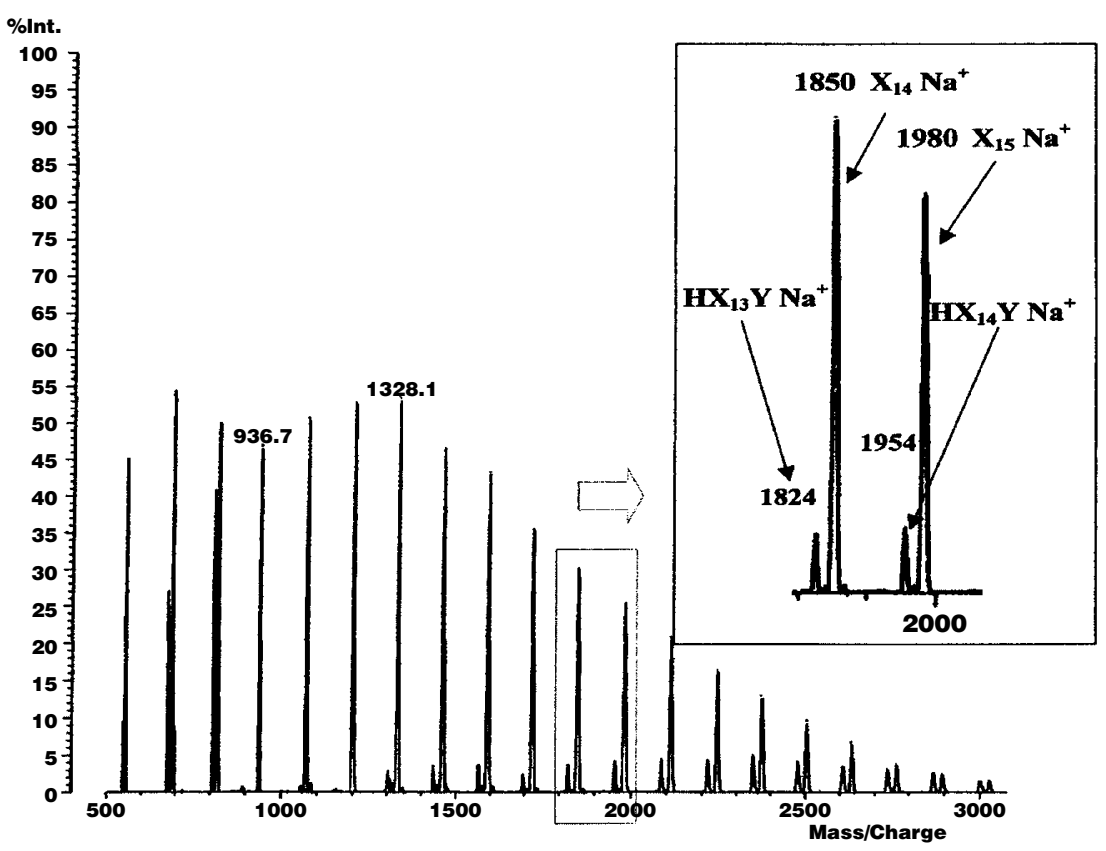

Figure 6. MALDI-TOF mass spectrum of poly(DTC) obtained by the polymerization of DTC carried out at $120^{\circ} \mathrm{C}$ in bulk, in the presence of $\mathrm{Sn}\left(\mathrm{OCH}_{2} \mathrm{CH}\left(\mathrm{CH}_{3}\right) \mathrm{CH}_{2} \mathrm{O}\right)(1 \mathrm{~mol} \%)$ and a small amount of 2,2-dimethylpropane-1,3-diol $(0.01 \mathrm{~mol} \%)$, where: $\mathrm{X}=$ $\mathrm{OCH}_{2} \mathrm{C}\left(\mathrm{CH}_{3}\right)_{2} \mathrm{CH}_{2} \mathrm{OC}(\mathrm{O}), \mathrm{Y}=\mathrm{OCH}_{2} \mathrm{C}\left(\mathrm{CH}_{3}\right)_{2} \mathrm{CH}_{2} \mathrm{OH}$.

the MALDI-TOF mass spectrum (Figure 5b) two series of signals are present. Much more intensive signals can be assigned to poly(DTC) macromolecules terminated with neopentyl glycol $\left(M_{\mathrm{n}}=1840\right)$, and less intensive signals to macromolecules terminated with 1,2-propylene glycol $\left(M_{\mathrm{n}}=1800\right)$. The elimination of macrocyclization was probably due to the presence of a small amount of 1,2-propylene glycol in the propylene carbonate solvent.

It is worth mentioning, that in the transesterification reaction between propylene carbonate and 1,6hexanediol carried out in the presence of $\mathrm{Sn}(\mathrm{Oct})_{2}$ at $150-160^{\circ} \mathrm{C}$ using an azeotropic solvent (xylene) exclusively linear polycarbonate macromolecules were formed. ${ }^{23}$

\section{CONCLUSIONS}

The polymerization of six-membered cyclic carbonate initiated with dialkoxytin(II) catalysts proceeds in a high rate leading predominantly to macrocyclic products. The polymerization was shown to follow a "coordination-insertion" mechanism, in which only one kind of the $\mathrm{Sn}-\mathrm{O}$ bond in the dimeric catalyst is active in the propagation reaction.

In contrast to cyclic ester monomers, symmetric carbonate linkages can be cleaved between the carbonyl group and oxygen atom at both sides and during polymerization the cyclic stannane catalyst can be formed in situ. The presence of diol or water suppresses the formation of macrocycles and polymeric products terminated with hydroxyl groups can be obtained.

\section{REFERENCES}

1. K. Stridsberg, M. Ryner, and A.-C. Albertsson, Macromolecules, 33, 2862 (2000).

2. G. Montaudo, M. S. Montaudo, C. Puglisi, F. S. N. Spassky, A. LeBorgne, and M. Wisniewski, Macromolecules, 29, 6461 (1996).

3. P. Maravigna and G. Montaudo, in "Comprehensive Polymer Science”, 2nd ed, G. Allen and J. C. Bevington, Ed., Pergamon Press, Oxford, 1989, p 5.

4. S. Sosnowski, S. Słomkowski, A. Lorenc, and H. R. Kricheldorf, Colloid Polym. Sci., 280, 107 (2002).

5. D. Knani, A. L. Gutman, and D. Kohn, J. Polym. Sci., Part A: Polym. Chem., 31, 1221 (1993).

6. A. Cordova, T. Iversen, K. Hult, and M. Martinelle, Polymer, 39, 6519 (1998).

7. A. Kowalski, A. Duda, and S. Penczek, Macromol. Rapid Commun., 19, 567 (1998).

8. A. Kowalski, A. Duda, and S. Penczek, Macromolecules, 33, 689 (2000).

9. H. R. Kricheldorf, A. Stricker, and M. Lossin, J. Polym. Sci., Part A: Polym. Chem., 37, 2179 (1999).

10. R. Gsell and M. Zeldin, Synth. React. Inorg. Met.-Org. Chem., 6, 11 (1976).

11. A.-C. Albertsson and M. Sjoeling, J. Macromol. Sci., Pure Appl. Chem., 29, 43 (1992).

12. A. Kowalski, J. Libiszowski, A. Duda, and S. Penczek, Macromolecules, 33, 1964 (2000).

13. H. R. Kricheldorf and A. Stricker, Polymer, 41, 7311 (2000).

14. H. Jacobson and W. H. Stockmayer, J. Chem. Phys., 18, 1600 
(1950).

15. M. Veith, P. Hobein, and R. Rosler, Z. Naturforsch., B: Chem. Sci., Teil B, 49, 1067 (1989).

16. B. G. McBurnett and A. H. Cowley, Chem. Commun., 17 (1999).

17. P. Kane, D. Fayne, D. Diamond, S. E. J. Bell., and M. A. McKervey, J. Mol. Model., 4, 259 (1998).

18. T. Fieldberg, P. B. Hitchcock, M. F. Lappert, S. J. Smith, and A. J. Thorne, Chem. Commun., 939 (1985).
19. R. C. Methrothra and V. D. Gupta, J. Organomet. Chem., 4, 145 (1965).

20. M. Ryner, A. Finne, and A.-C. Albertsson, Macromolecules, 34, 7281 (2001).

21. S. Hiki, M. Miyamoto, and Y. Kimura, Polymer, 41, 7369 (2000).

22. J. E. Kemnitzer, S. P. McCarthy, and R. A. Gross, Macromolecules, 26, 6143 (1993).

23. G. Rokicki and T. Kowalczyk, Polymer, 41, 9013 (2000). 